\title{
The effect of intensive fattening of bulls with a high-concentrate diet on ruminal mucosa - a morphometric study
}

\author{
Julius Černík ${ }^{1}$, Eva Štercová ${ }^{2}$ Jan Šterc ${ }^{3}$, Petr Fictum ${ }^{1}$, Jiří Luňáček ${ }^{4}$, Roman Halouzka ${ }^{1}$ \\ ${ }^{1}$ Faculty of Veterinary Medicine, Department of Pathological Morphology and Parasitology, \\ ${ }^{2}$ Faculty of Veterinary Hygiene and Ecology, Department of Nutrition, Animal Husbandry and Animal Hygiene, \\ University of Veterinary and Pharmaceutical Sciences Brno, Czech Republic \\ ${ }^{3}$ CERVUS s.r.o., Olomouc, Czech Republic \\ ${ }^{4}$ Faculty of Business and Management, Department of Economy, Brno University of Technology, \\ Czech Republic \\ Received October 8, 2010 \\ Accepted April 6, 2011
}

\begin{abstract}
The aim of the study was to identify the effect of fattening of experimental Simmental bulls (a total of 10 animals) with a high-concentrate diet on ruminal mucosa and dimensions of ruminal papillae, and to assess the intensity of keratinization of papillary epithelium. The experimental period lasted from weaning to slaughter (359 days). Histopathological and morphometric examinations of ruminal mucosa indicated that the ruminal papillae of bulls from the experimental group were better developed (long with a lower degree of keratinization) compared to the control group. Significant differences between the experimental and control groups were found in the length of ruminal papillae $(p=0.005)$, width of stratum corneum $(p=0.034)$ and degree of mucosal keratinization on the surface of ruminal papillae $(p=0.014)$. Conclusive results of morphometric analysis prove the facility of the use of morphometrics as a method useful for veterinary pathology, mainly for the accuracy of the histological diagnosis.
\end{abstract}

Cattle, rumen, grain, morphometry, ruminal epithelium

The rumen in young suckling ruminants is small, about half the size of the abomasum. It undergoes significant morphological and physiological changes during the growth of the animal. In cattle, the ratio between the rumen and abomasum of 4 week-old-calves is 1:2, at 8 weeks of age 1:1, at 3 months 2:1 and in the adult cattle 9:1 (Rosenberger 1964).

The ruminal mucosa consists of a multilayer squamous epithelium with significant keratinisation. The lining has papillae of tongue-like shape on the surface with the length of $1-13 \mathrm{~mm}$ and width of $0.5-3 \mathrm{~mm}$, and these significantly increase the surface of the ruminal epithelium (Hofmann and Schnorr 1982; Langer 1988; Frappier 2006). The longest papillae are located in the blunt sacs, at the bottom of the ventral sac and the bottom of the ruminal antrum. The length decreases towards the columns and on the edge there are only low papillae or they disappear completely (Jelínek 1995; König et al. 2004).

The morphological properties of the gut lining including the size of papillae and their quantity are variable. The pathogenesis of morphological adaptation of the ruminal mucosa depends on several factors, such as age of the animal, composition and quality of feed, fibre content, and type, concentration and ratio of volatile fatty acids (VFA), ruminal content $\mathrm{pH}$, intensity of fermentation processes in the rumen, etc. (Zitnan et al. 2003; Radostits et al. 2007). The ruminal papillae are rudimentary in newborn and young animals, therefore the mucosa is relatively smooth and pale (Jelínek 1995; Amaral et al. 2005). Under physiological conditions, mature papillae are covered with a thin layer of keratinising squamous cells (Frappier 2006). Morphology of the ruminal mucosa relates to concentrations of volatile fatty acids (VFA), mainly those of butyric and propionic acids. It is characterised by a process of continual changes, from regression to proliferation. The 
animals fed mainly grain have short, narrow and dark ruminal papillae. Microscopically there is acanthotic, hyperkeratotic or parakeratotic epithelium with hyperpigmentation (Barker et al. 1993; Radostits et al. 2007).

Cereals have a high content of saccharides. The fattening of cattle with grains is the most intensive form of meat production. Animals fed high concentrate diets show high intensity of growth and high daily weight gain. In the Czech Republic, the system has been used in a lower slaughter weight fattening cattle, so-called "baby-beef" (Chládek 1998). Our hypothesis was that ruminal papillae would develop more intensively in the HC group of bulls.

There is absence of literature describing the effects of high-concentrate diet on ruminal mucosa of fattening bulls. The aim of this study was to identify the effect of fattening of bulls with a high concentrate diet on ruminal mucosa and dimensions of ruminal papillae, to assess the intensity of keratinization of papillary epithelium, and to compare the obtained results with those of fattening with forage based feeds.

\section{Materials and Methods}

The experiment was performed with 10 Czech Simmental bulls divided in two groups of 5 animals. Experimental bulls (HC group) were fed a concentrate diet (75.0-83.6\% of concentrate on dry matter basis) with a low content of forage. The control group were fed a total mixed ration based on maize silage, a typical feed on that farm. The experiment took place from weaning to the slaughter of bulls (359 days). The average age of the HC bulls at weaning was 114 days, control bulls were weaned at an average age of 115 days. Average live weight at weaning of the $\mathrm{HC}$ and control bulls was $139.78 \mathrm{~kg}$ and $138.56 \mathrm{~kg}$, respectively. Average age at slaughter of the $\mathrm{HC}$ and control bulls was 473 and 474 days, respectively. Average live weight at slaughter in the HC and control group was $570.94 \mathrm{~kg}$ and $543.33 \mathrm{~kg}$, respectively. The bulls were slaughtered in a standard way in abattoir and their organs were subjected to veterinary and hygienic examinations and morphological assessment.

Samples for histopathological and morphometric examination were collected after the slaughter of the animals from the rumen, from the bottom of saccus ruminis ventralis every time from the same place. The size of the samples was approximately $1 \times 1 \times 0.5 \mathrm{~cm}$. The tissue was fixed for a period of $72 \mathrm{~h}$ after the collection in $10 \%$ formalin in a wide neck bottle, whereas the ratio of the quantity of fixation fluid to the fixed tissue was approximately 20:1. Afterwards, the samples were processed using the common paraffin method, stained with haematoxylin-eosine (Clark 1981) and evaluated by a light microscope.

The histopathological mounts of the rumen tissue were furthermore morphometrically examined by image analysis using Soft Imaging System Cell F (Imaging Software for Life Science Microscopy, OLYMPUS Soft Imaging Solutions). Five variables were measured in three papillae in each section (Knott et al. 2004): the length of the papilla (from the base to the apex), the width of the papilla (the distance in the whole extent of the papillar base - also with the epithelium), the width of the epithelium (the distance between the external border of lamina propria mucosae and internal border of stratum corneum at the papillar base), the width of stratum corneum (SC) from the external end of stratum lucidum to the papillary surface and also keratinisation on the surface of the papillae (above the external border of the stratum corneum). The measurements were performed using the function of arbitrary line (Al), the shortest linear distance between the selected initial and final point of the measured object, decisive establishment of the distance between two points. During the measurement of more objects in the visual field, it also has a comparison function, based on which the software creates a statistical report.

Statistical data for morphometry (average values of measurement and standard deviation) were obtained along with the measurements done using the aforementioned computer programme. Measured values were also processed with the statistical software STATISTICA, version 9. Two sample $t$-tests were used and all 10 values for the group and the measured diameter were compared in order to determine whether the results of the measurement in one group are significantly different from the results of the measurements in the second group (with the significance level of 0.05). For such small number of samples, normal distribution is not anticipated. For less than 20 samples, the validity of $t$-test can be out of focus. Therefore, non-parametric Mann-Whitney U-test was also used.

\section{Results}

During the microscopic inspection of rumen in the HC group we found following changes in ruminal mucosa: long narrow ruminal papillae, a lower degree of keratinisation of ruminal mucosa than in the control group, dilatation and hyperaemia of capillaries of the lamina propriae mucosae and submucosis and edema of submucosis (Plate V, Fig.1). 
Table 1. Morphometric values of the ruminal mucosa in bulls from high-concentrate and control groups

\begin{tabular}{|c|c|c|c|c|c|}
\hline & $\begin{array}{l}\text { Length of Al } \\
\text { papillae }(\mu \mathrm{m})\end{array}$ & $\begin{array}{c}\text { Width of Al } \\
\text { papillae }(\mu \mathrm{m})\end{array}$ & $\begin{array}{c}\text { Width of } \mathrm{Al} \\
\text { epithelium }(\mu \mathrm{m})\end{array}$ & $\begin{array}{l}\text { Width of Al } \\
\text { Sc }(\mu \mathrm{m})\end{array}$ & $\begin{array}{c}\text { Al of } \\
\text { kerat. }(\mu \mathrm{m})\end{array}$ \\
\hline \multicolumn{6}{|l|}{ HC group } \\
\hline Mean & 2335.36 & 665.61 & 59.33 & 12.84 & 15.15 \\
\hline Maximum & 734.30 & 323.83 & 28.34 & 9.94 & 7.15 \\
\hline Minimum & 3997.96 & 1101.02 & 116.84 & 15.65 & 25.89 \\
\hline S.D. & 1129.31 & 256.08 & 22.75 & 2.04 & 5.06 \\
\hline \multicolumn{6}{|c|}{ Control group } \\
\hline Mean & 1323.20 & 737.94 & 59.47 & 15.56 & 29.50 \\
\hline Maximum & 610.84 & 390.22 & 27.58 & 9.66 & 8.47 \\
\hline Minimum & 1218.77 & 592.41 & 56.08 & 14.84 & 25.01 \\
\hline S.D. & 589.42 & 311.46 & 22.24 & 4.25 & 20.64 \\
\hline
\end{tabular}

Al - arbitrary line, Sc - stratum corneum, kerat. - keratinisation, S.D.- standard deviation

Count of measurements in all variables: 15

In control group we found long narrow papillae (larger then in the HC group) with a higher degree of keratinisation than in the HC group and no pathological changes (Plate V, Fig. 2).

Detailed morphometric values are given in Table 1.

Significant differences between the high-concentrate and control groups were found (by the Student's $t$-test) in the length of ruminal papillae $(p=0.005)$, width of stratum corneum $(p=0.034)$ and the extent of mucosal keratinization on the surface of ruminal papillae ( $p=$ $0.014)$. The verification of statistic results by Mann-Whitney U-test confirmed the results obtained by Student's $t$-test: lenght of papillae $p=0.0128$, width of stratum corneum $p=$ 0.0500 and width of keratinisation $p=0.0074$.

\section{Discussion}

Length and width of papillae detected in this study were within the physiological range (Hofmann and Schnorr 1982; König et al. 2004). However, as other measures obtained were variable and depended on many factors, no standard physiological values were found for them. Therefore these measures were compared with the same indicators measured in the control group.

Feeding the high concentrate diet led to the development of long papillae that were longer but thinner than the papillae observed in the control group. Keratinization of papillae in the high-concentrate group was less extensive compared to the control animals. Hyperaemia of capillaries and oedema of mucosa and submucosa that were observed in the HC animals have been reported to occur in the initial phase of ruminal acidosis (Barker et al. 1993; Radostits et al. 2007).

Papillae of ruminal mucosa in the $\mathrm{HC}$ bulls were more developed. They were longer and showed a lower extent of keratinization as compared with the control group. Differences between the groups were small and changes did not significantly deviate from the physiological values (Hofmann and Schnorr 1982). The development of long and wide papillae with low degree of keratinization indicated a desired enlargement of ruminal epithelium surface for better absorption and utilization of nutrients. Similar results were reported also by other authors in horned cattle (Zitnan et al. 2003; Khan et al.2008), in arctic ruminants (Knott et al. 2004) and in goats (Amaral et al. 2005). However, the hypothesis that long-term fattening with a high concentrate diet causes atrophy, hyperkeratosis and parakeratosis of ruminal mucosa (Hofmann and Schnorr 1982; Baker et al. 1993; 
Radostits et al. 2007) was not confirmed. This indicates that reduced supply of fibre in the $\mathrm{HC}$ group did not impair physiological development of ruminal mucosa.

The liquid content of rumen in the HC bulls showed a ruminal dysfunction (mild acidosis), which was confirmed also by tests of ruminal fluid, experimental animals showed significantly lower $\mathrm{pH}$ of ruminal fluid, higher total titration acidity and highly significantly higher percentage of total VFA and percentage of propionic acid and valeric acid, and, on the other hand, lower percentage of acetic acid and butyric acid. However, a significant increase of lactic acid concentration (Štercová et al. 2006) was not observed, which probably prevented the development of necrosis and inflammation of ruminal mucosae typical for ruminal acidosis.

In order to optimize ruminal fermentation process, animals should be given a balanced diet (Rosenberger 1964; Štercová et al. 2006, 2008; Radostits et al. 2007). Lack of structural fibre and excess of easily fermentable carbohydrates in feed can cause disorders of ruminal fermentation in fattening animals, which leads to the development of ruminal acidosis that can turn into metabolic acidosis. A low proportion of structural fibre can also cause forestomach atony or hyperkeratosis and parakeratosis of ruminal mucosa (Barker et al. 1993; Radostits et al. 2007). After the ingestion of feed with high content of carbohydrates, Gram-positive microflora (streptococci, lactobacilli) proliferate in the rumen, which results in the production of lactic acid (Nocek 1997; Owens et al. 1998). Lactic acid then causes necrosis and inflammation of ruminal mucosa (Barker et al. 1993; Radostits et al. 2007). Alteration of ruminal fermentation can even induce inflammation and abscess formation in the liver and other parenchymatous organs (Barker et al. 1993; Nagaraja and Chenggappa 1998), laminitis (Nocek 1997) and disorders of the nervous system (Barker et al. 1993; Radostits et al. 2007).

The obtained results indicate that the desired enlargement of ruminal epithelium surface for better absorption and utilization of nutrients in HC group was achieved.

\section{Acknowledgements}

We would like to thank Mrs. Ana Alačková and Markéta Lišková (University of Veterinary and Pharmaceutical Sciences, Brno, Czech Republic) for the processing of histopathological samples.

\section{References}

Amaral CMC, Sugohara A, Resende KT, Machado MRF, Cruz C 2005: Performance and ruminal morphologic characteriristics of Saanen kids fed ground, pelleted or extruded total ration. Small Ruminant Res 58: 4754

Barker KI, Dreumel AA, Palmer N 1993: The Alimentary system. In: Jubb KVF, Kennedy PC, Palmer N (Eds.): Pathology of domestic animals vol. 2. Academia Press, Inc. San Diego, pp. 41-51

Chládek G 1998: Meat efficiency of bullocks of the black pied breed finished to a lower slaughter weight. Czech J Anim Sci 43: 537-540

Clark G 1981: General Methods. In: Clark G (Ed.): Staining procedures. Wiliams and Wilkins, Baltimore, USA, pp. 23-25, 36-37

Frappier BL 2006: Digestive system. In: Eurell J, Frappier BL (Eds.): Dellmanns Textbook of Veterinary Histology. Blackwell Publishing, pp. 189-194

Hofmann RR, Schnorr B 1982: The functional morphology of proventriculi. Ferdinand Enke Verlag, Stuttgart, $170 \mathrm{p}$.

Jelínek K 1995: Development dynamics of the caprine forestomach in the postnatal period. Acta Vet Brno 64: 49-61

Khan MA, Lee HJ, Lee WS, Kim HS, Kim SB, Park SB, Baek KS, Ha, JK, Choi YJ 2008: Starch source evaluation in calf starter: II. Ruminal parameters, rumen development, nutrient digestibilities and nitrogen utilisation in holstein calves. J Dairy Sci 91: 1140-1149

Knott KK, Barboza PS, Bowyer RT, Blake JE 2004: Nutritional development of feeding strategies in arctic ruminants: digestive morphometry of reindeer and muskoxen. Zoology 107: 315-333

König HE, Sautet J, Liebich HG 2004: Digestive system. In: König HE, Liebich HG (Eds.): Veterinary Anatomy of Domestic Animals. Schattaver GmbH Stuttgart, pp. 311- 315

Langer P 1988: The mammalian herbivora stomach- comparative anatomy, function, evolution. G. Fischer Verlag, Berlin, 445 p. 
Nagaraja TG, Chenggappa MM 1998: Liver abscesses in feedlot cattle: A review. J Anim Sci 76: 287-298

Nocek JE 1997: Bovine acidosis: Implications on laminitis. J Dairy Sci 80: 1005-1028

Owens FN 1998: Acidosis in cattle. A review. J Anim Sci 76: 275-286

Radostits OM, Gay CG, Hinchcliff PD, Constable PD 2007: Diseases of the alimentary tract. In: Radostits OM, Done J, Stanley H (Eds.): Veterinary Medicine: a textbook of the diseases of cattle, sheep, pigs and goats. Elsevier Saunders, Edinburgh, pp. 328

Rosenberger G 1964: The clinical obtain of calves. Verlag Paul Parey, Berlin- Hamburg, 482 p.

Štercová E, Haas D, Krása A, Lepková R, Šterc J 2006: Effect of intensive fattening of bulls fed a high grain diet on selected health indicators. Acta Vet Brno 75: 209-218

Štercová E, Krása A, Lepková R, Šterc J 2008: The evaluation of growth and selected carcass and meat quality parameters in fattening bulls fed a diet based on concentrates or maize silage. Czech J Anim Sci 53: 368-376

Zitnan R, Kuhla S, Nurnberg K, Schonhuse U, Ceresnakova Z, Sommer A, Baran M, Greserova G, Voigt J 2003: Influence of the diet on the morphology of ruminal and intestinal mucosa and on intestinal carbohydrase levels in cattle. Vet-Med Czech 48: 177-182 
Plate V

Černík J. et al.: The effect of intensive... pp. 275-279

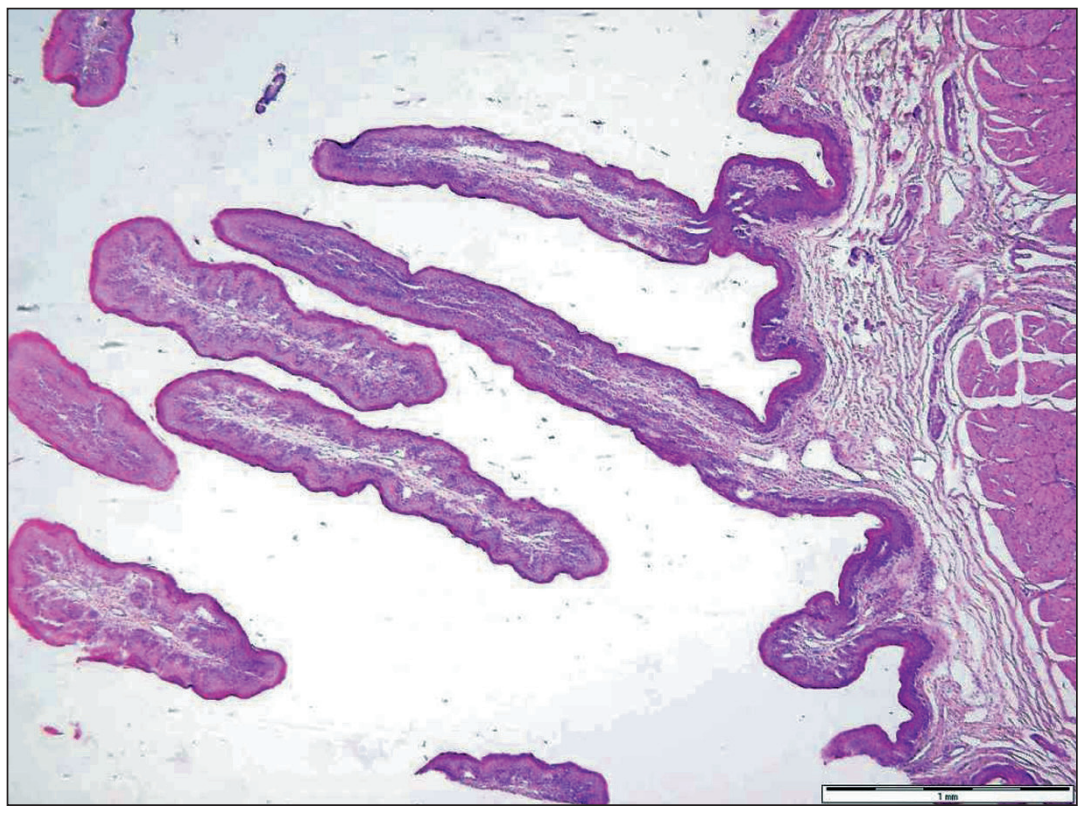

Fig. 1. Long ruminal papillae with moderate keratosis in experimental group of bulls. Haematoxylineosine. $\times 100$

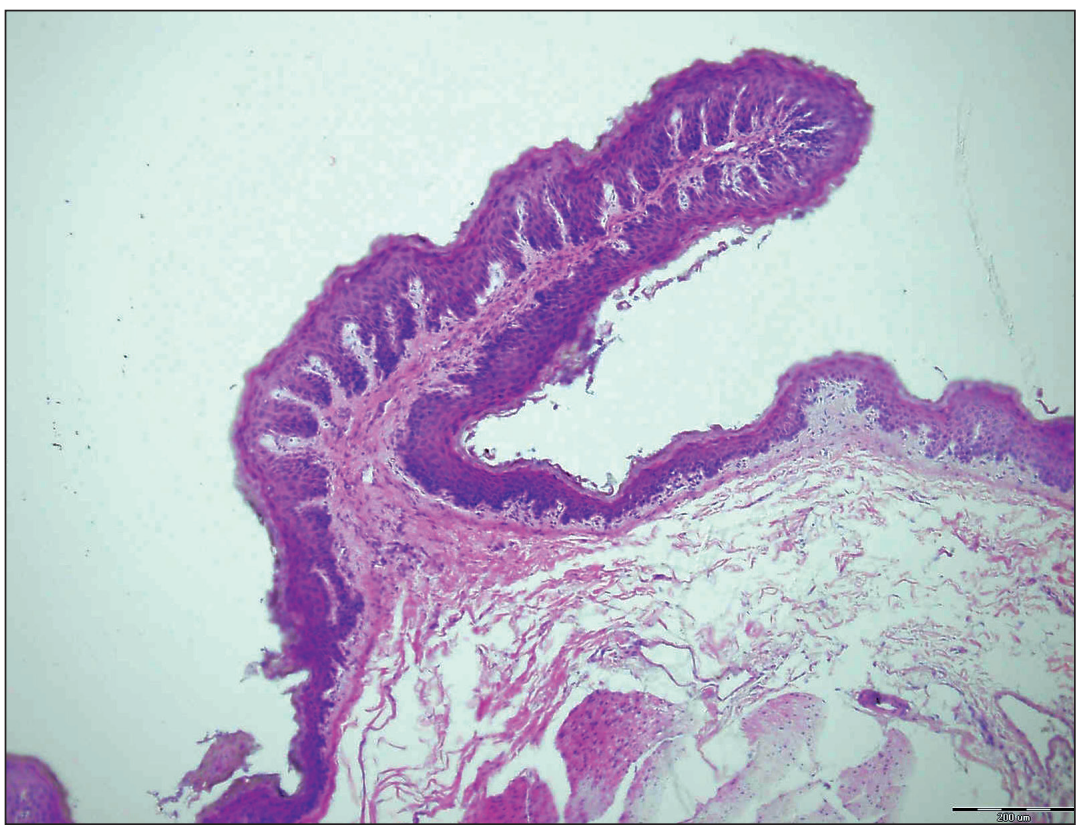

Fig. 2. The longer and wider ruminal papilla with stronger keratosis in control group of bulls. Haematoxylineosine. $\times 200$. 